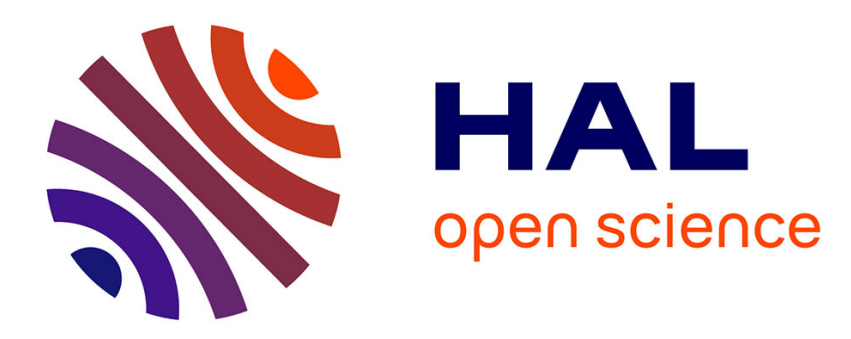

\title{
The Incidence of Non-Linear Consumption Taxes Clément Carbonnier
}

\section{To cite this version:}

Clément Carbonnier. The Incidence of Non-Linear Consumption Taxes. 2013. halshs-00872474

\section{HAL Id: halshs-00872474 https://shs.hal.science/halshs-00872474}

Preprint submitted on 13 Oct 2013

HAL is a multi-disciplinary open access archive for the deposit and dissemination of scientific research documents, whether they are published or not. The documents may come from teaching and research institutions in France or abroad, or from public or private research centers.
L'archive ouverte pluridisciplinaire HAL, est destinée au dépôt et à la diffusion de documents scientifiques de niveau recherche, publiés ou non, émanant des établissements d'enseignement et de recherche français ou étrangers, des laboratoires publics ou privés. 


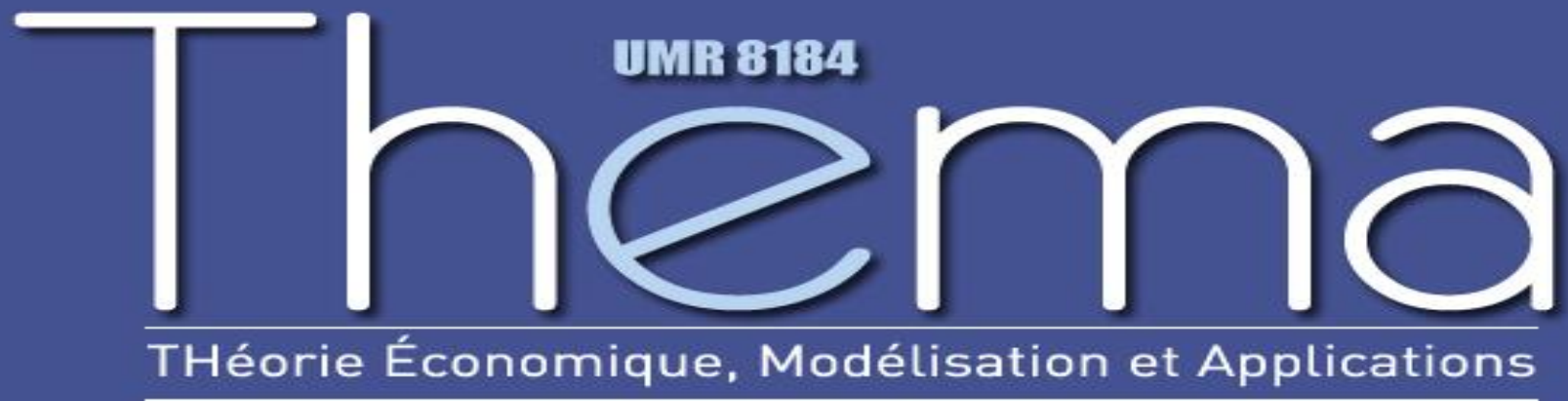

Thema Working Paper $n^{\circ}$ 2013-19

Université de Cergy Pontoise, France

The Incidence of Non-Linear Consumption Taxes

Clément Carbonnier

April, 2013 


\section{The Incidence of Non-Linear Consumption Taxes}

\section{Clément Carbonnier ${ }^{1}$}

Université de Cergy-Pontoise, THEMA and Sciences-Po, LIEPP

\section{Abstract}

The present article generalyses economic litterature on consumption tax incidence to general forms of consumption taxes. Previous studies were limited to the cases of per unit and ad valorem taxes. Three main contributions are provided. From a methodological point of view, the elasticity of the tax function is introduced as a new parameter to take the shape of general consumption tax schedules into account in different models of imperfect competition in a tractable manner. From a theoretical point of view, existing results on the difference of incidence of ad valorem and per unit consumption taxes are generalized to non-linear consumption taxes: the larger the elasticity of the tax function the weaker the share of the consumption tax beared by consumers. From an applied public economic point of view, it is shown how the regulator may put downwards prices on very uncompetitive markets by increasing the elasticity of the consumption tax on a targeted window of producer prices.

Keywords: Consumption taxes; Imperfect Competition; Tax Incidence; Efficiency.

JEL: H21; H22; H24; H32.

\footnotetext{
${ }^{1}$ Université de Cergy-Pontoise - THEMA, 33 bd du port, 95000 Cergy-Pontoise cedex Tel: +33-134256321; Fax: +33-134256233; Email: clement.carbonnier@u-cergy.fr.
} 


\section{Introduction}

Taxes are not always beared by the agent designed to do so by fiscal authorities. Economic analyses consider this at least since Quesnay (1759) explained that each and every tax of the French ancien régime is eventually beared by landlords. Afterwards, different bearers for different taxes has been considered by Smith (1776) then Ricardo (1821) (e.g.: luxury good consumers, landlords, capitalists at least for the share of profit which is not constituted by risk premium) then the question of tax incidence has become a major issue of economic analysis. The present article generalyses existing economic litterature on consumption tax incidence to general forms of consumption taxes. Previous studies were limited to the cases of per unit and ad valorem taxes. Here are considered any tax schedule depending on the price: as consumption is mainly anonymous, tax schedules do not depend on the quantities purchased.

Three main contributions are provided. From a methodological point of view, the elasticity of the tax function is introduced as a new parameter to take the shape of general consumption tax schedules into account in different models of imperfect competition in a tractable manner. From a theoretical point of view, existing results on the difference of incidence of ad valorem and per unit consumption taxes are generalized to non-linear consumption taxes: the larger the elasticity of the tax function the weaker the share of the consumption tax beared by consumers. From an applied public economic point of view, it is shown how the regulator may put downwards prices on very uncompetitive markets by increasing the elasticity of the consumption tax function on a targeted window of producer prices.

The incidence of consumption taxes is of main importance as much for equity reasons as for efficiency ones. It measures the way a tax burden is shared between different economic agents (producers and consumers in the case of consumption taxes), which determines the distributive impact of fiscality. It also measures the way consumptions taxes impacts the total output, and therefore the deadweight loss of indirect taxation. Standart results state that consumers bear the whole tax burden in perfect competiton in the long run, but that it may be shared with producers in the short run or when competition is imperfect (Fullerton and Metcalf (2002)). In that case, the consumer share of the tax burden decreases with respect to the demand elasticity and increases with respect to the elasticity of the marginal cost of production (Carbonnier (2009)). Furthermore, tax incidence depend on the structure of competition and the consumer share may even be greater than 100\%. This has been confirmed theoretically by Stern (1987) and Besley 
(1989) for homogenous products and Anderson et al. (2001b,a) for heteregenous products; it has been also empirically confirmed by Besley and Rosen (1999) and Carbonnier (2007, 2009, 2011).

Furthermore, the form of the tax itself influence its incidence. This has been noticed early in the economic literature. At the begining of the XIX ${ }^{\text {th }}$ century, Cournot (1838) allready found a difference between incidences of unit and ad valorem consumption taxes under monopoly. Since, only these two kind of consumption taxes has been studied. If these two taxes are equivalent under perfect competition, the literature has shown that consumers bear a large share of unit taxes than ad valorem taxes. Wicksell (1896) demonstrated this result in the case of a monopoly with constant marginal costs, Suits and Musgrave (1953) for all monopolies, Delipalla and Keen (1992) under Cournot oligopoly with conjectural variations and Anderson et al. (2001b,a) under Bertrand oligopoly. This result has been empirically confirmed by Delipalla and O'Donnell (2001) and Carbonnier (2011) using respectively the european tabacco market and the French alcohol market.

The intuition behind this very general result is quite simple. Whatever the producer price, the amount of the tax per unit of output is the same. However, the tax itself decreases if the producer decreases its own price in the case of ad valorem consumption taxes. Threfore, ad valorem consumption taxes subsidies the producer price decreases, adding a tax decrease to the producer price decrease. This incentive make price decreases more profitable for producer in the case of ad valorem consumption taxes, and leads to lower consumption prices for the same level of tax revenue.

However, these two kinds of taxes are not the only possible ways for taxing consumption, and more complex schedules might be setted. For existing example, the French tax on oil (TIPP for Taxe à l'Importation sur les Produits Pétroliers) was settle with a special schedule between October $1^{\text {st }} 2001$ and July 212002 and the temptation to reset it is still alive. It was a per unit tax whose value decreases with respect to the values of the Brent baril (floating TIPP). More generally, governments may want to use fiscal tools to smoothe price volatility of certain very price volatile goods. The present paper shows that such tax schedule would be inflationary. In addition, European tax systems uses different VAT rates for different goods. Mainly, all countries have at least a full rate and a reduced rate, the latter for different goods and services among whom first necessisty consumption. Yet it could be considered for example that ordinary meat is first 
necessity consumption but not luxury meat, and in that case the government would want to tax meat at different rate (full or reduced) depending on its price.

The intuition about the per unit/ad valorem result puts forward the importance of the variation of the tax with respect to the producer price. The present article propose a usefull parameter to measure it: the elasticity of the tax function. Different model of imperfect competition are derived to understand the impact of this parameter on the incidence of consumption taxes.

The remainder of the article is composed as follow. Section 2 introduces the elasticity of the tax function, and gives some examples of its value for different existing or potential consumption taxes (2.1). Then, the theoretical methodology is presented (2.2) through the cases of perfect competition and monopoly: the elasticity of the tax function has no impact on tax incidence under perfect competition, but the consumer share of the tax burden decreases with respect to it under monopoly. Section 3 shows the same result in the case of markets for homogenous goods, both in the short run (3.1) and in the long run (3.2). Section section 4 analyses the case of markets for heterogenous goods. The result stands in the short run (4.1) but not always in the long run (4.2). Section 5 concludes, discusses the consequences in matter of welfare and optimal taxation and draws the perspective for further studies.

\section{Theoretical framework}

The introduction presented the intuition behind the incidence difference between per unit and valorem consumption taxes. The key property is the way the tax itself varies when the producer price varies. Indeed, ad valorem consumption taxes induces lower consumer price than unit taxes because the unit tax is independant from the producer price when the ad valorem tax increases with respect to the producer price. Therefore, ad valorem taxes generate a larger incentive for producers to decrease their price, because it decreases also the amount of tax due. This property of the consumption tax should be synthetized in a parameter which could be introduced in models of market equilibrium. In that purppose, the present section introduces such a parameter: the elasticity of the tax function. The first subsection presents this elasticity as well as examples of non-linear consumption taxes. The following subsection presents the theoretical strategy thrgough the cases of perfect competition and monopoly. 


\subsection{The elasticity of the tax function}

First of all, the consumption tax function $T$ is defined as the function giving the consumer price $q$ from the producer price $p$ (the actual tax being the difference between the two). It allows to consider every kind of consumption tax. For example, the per unit tax function is $T(p)=p+t$ where $t$ is the actual tax per unit and the ad valorem tax function is $T(p)=(1+\tau) p$ where $\tau$ is the actual rate of ad valorem consumption tax. Given this tax function, the key parameter about the form of the consumption tax is the elasticity of consumer price to producer price $\epsilon_{T}=\frac{p}{q} \frac{\partial q}{\partial p}=\frac{p}{T(p)} T^{\prime}(p)$. This elasticity gives the curvature of the tax function. For ad valorem consumption taxes, this elasticity is equal to one: $\epsilon_{T}($ ad valorem $)=\frac{p}{(1+\tau) p}(1+\tau)=1$. For per unit consumption taxes, this elasticity is lower than one: $\epsilon_{T}($ per unit $)=\frac{p}{p+t}<1$.

Other kinds of consumption taxes are possible, even if - at our knowledge - no fiscal system has adopted them yet. A piecewise proportionnal consumption tax would have an elasticity equal to one except at the price threshold for the coefficient change where it is equal to infinity. Consumption

taxes with a polynomial shape $T(p)=A p^{\beta}$ have elasticity equals to $\beta: \epsilon_{P o l(\beta)}=\frac{1}{A p^{\beta-1}} \beta A p^{\beta-1}=\beta$. Therefore, the consumption tax may increase strongly with respect to the producer price if $\beta>1$. The extreme case is the exponential consumption tax $q=A e^{p}$ whose elasticity is equal to $p$ : $\epsilon_{E x p}=\frac{p}{A e^{p}} A e^{p}=p$. At the opposite, it may be chosen that the consumption tax is used to smoothe the producer price volatility with an elasticity inferior to 1 , it is the cas of polynomial consumption taxes with $\beta$ lower than one.

Furthermore, the example of non-linear presented in the introduction may be explorated in this context. Let say for example that government want to tax at reduced rate meat under ten euros per kilogram and at the full rate above forty. Between, the tax rate may be linear increasing or smoothly increasing (the actual example consider a cubic function of the producer price). Figure 2.1 shows these two consumption taxes and their elasticity.

It appears that these taxes - reduced rate for low prices and full rate for high prices - presents elasticity of the tax function significantly above one inside the window between the end of reduced rate and the begining of full rate. It appears in such case that for a fixed difference between reduced and full rates, the thiner the window, the larger the elasticity of the tax function.

This eslasticity of the tax function matters because it gives the link between consumer preferences and variations of the producer price. Indeed, consumers behavior depend on their consumption and their budget constraint. Therefore, from their preferences derives the elasticity of 


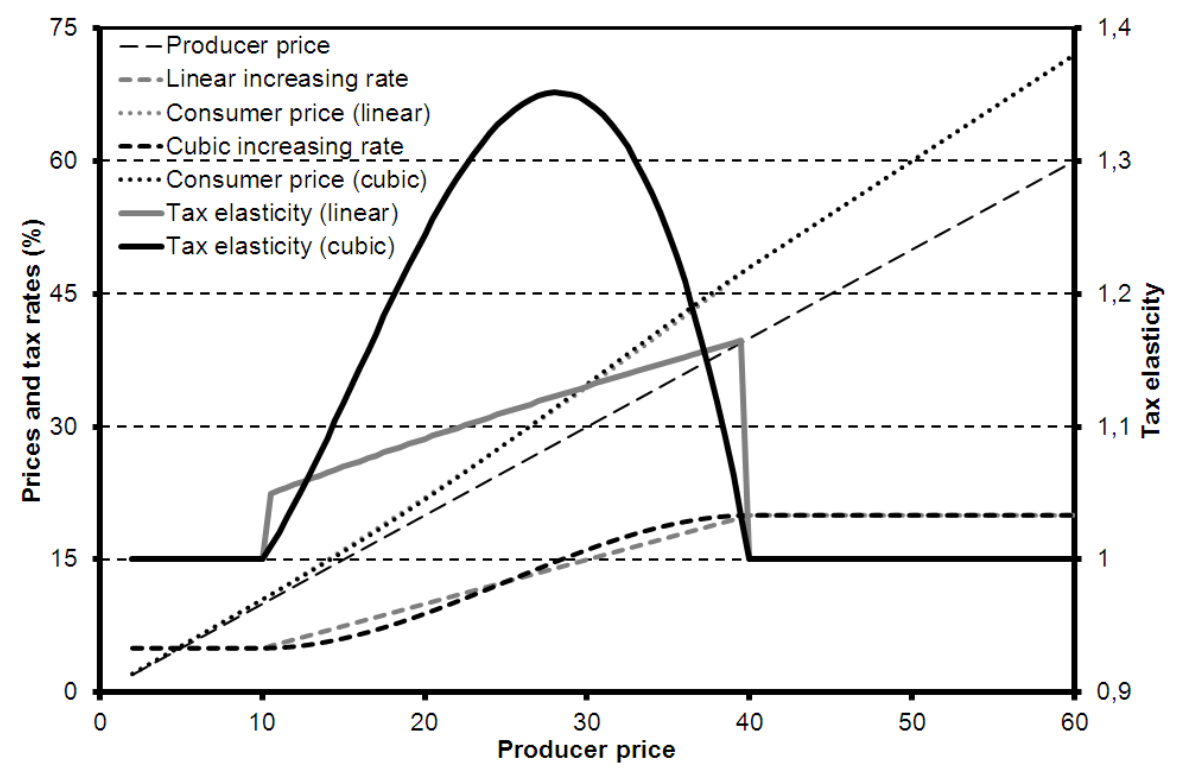

Figure 1: The elasticity of tax function for a variable rate consumtion tax

demand with respect to the consumer price $\epsilon_{q}$. However, the behavior of the producers depend on the reaction of the demand to changes in the producer price $\epsilon_{p}$. The relation between the two elasticities of the demand is given by equation 1 .

$$
\epsilon_{p}=\epsilon_{T} \epsilon_{q}
$$

Indeed, $\epsilon_{p}=\frac{p}{Y} \frac{\partial Y}{\partial p}=\frac{p}{q} \frac{\partial q}{\partial p} \frac{q}{Y} \frac{\partial Y}{\partial q}=\epsilon_{T} \epsilon_{q}$. It is how the elasticity of the tax function is inserted into the different models.

\subsection{Theoreticall methodology}

In the following, a strategy is adopted to understand the influence of the shape of the tax function - the elasticity of the consumer price to the producer price on tax incidence. First of all, a given equilibrium $E_{0}$ is considered with a producer price $p_{0}$, a consumer price $q_{0}=T_{0}\left(p_{0}\right)$ and a quantity produced $Y_{0}$. Then, the shape of the tax function is changed as $T_{1}$ in a such way that the new equilibrium $E_{1}$ has the same consumer price $q_{1}=q_{0}=q$ than $E_{0}$. It should be noticed that at this new equilibrium, the quantity produced on the market is $Y_{1}=D\left(q_{1}\right)=D\left(q_{0}\right)=Y_{0}=Y$; hence, the marginal cost of producers and the demand elasticity are the same at the two equilibria.

The only variables which vary because of the change in the shape of the tax are the producer price $p_{1}$ and consequantly the tax revenue $F_{1}=Y\left(q-p_{1}\right) \neq Y\left(q-p_{0}\right)=F_{0}$. If $p_{1}>p_{0}$, then 
$F_{1}<F_{0}$ and the change in the form of the tax decreases the efficiency of the consumption tax: for the same quantity produced and the same consumer price, the tax revenue is lower; reciproquely, for the same tax revenue, the consumer price is larger and the quantity produced lower. For reciproqual reasons, if $p_{1}<p_{0}$, then $F_{1}>F_{0}$ and the change in the shape of the tax increases the efficiency of the consumption tax.

Some results may be derived immediatly. Very simple examples of this methodology are given by the study of the two polar cases of perfect competition and monopoly. Figure 2 shows the case of perfect competition.

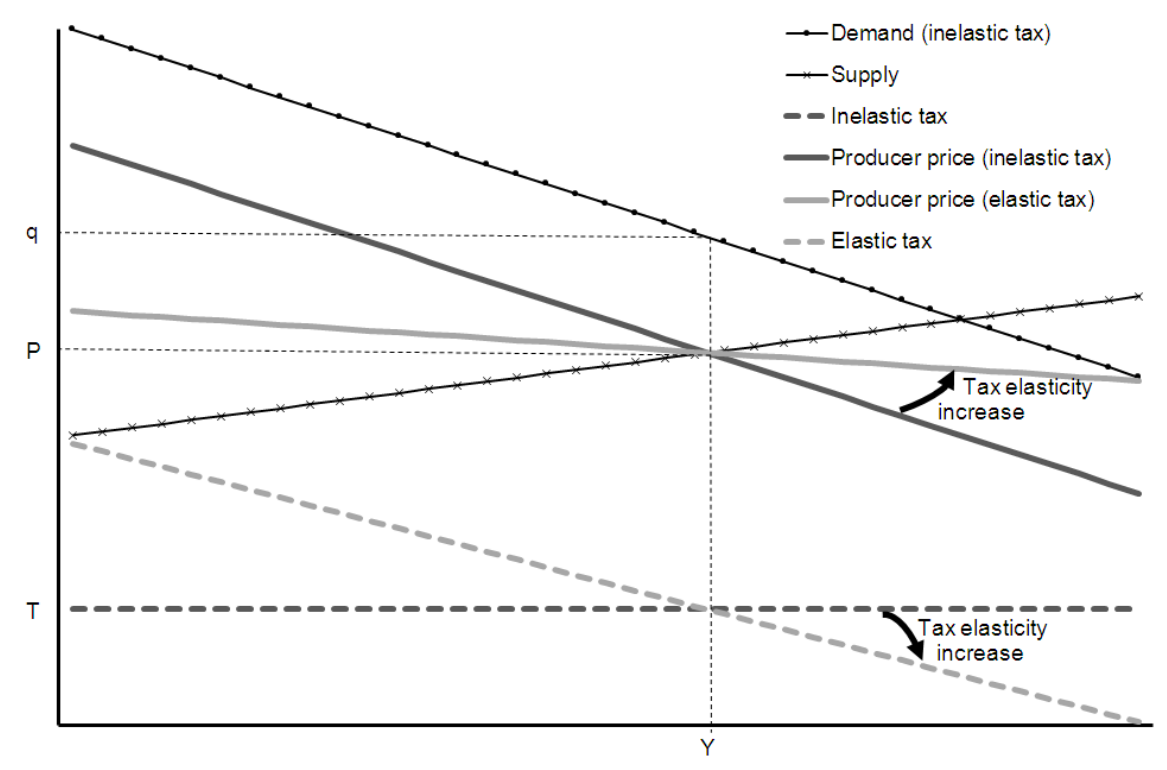

Figure 2: The elasticity of tax function for a variable rate consumtion tax

Under perfect competition, the output $Y$ is given by the intersection of the producer price (solid dark grey) and the marginal cost (thin crossed black line), the consumer price (thin dotted black line) being the inverse demand for this output. Changing the tax function $T_{0}$ for another $T_{1}$ more elastic but with the same output at equilibrium consists in drawing a new producer price curve (solid light grey) with a lower shape but cutting the marginal cost curve at the same value of output $Y$. Consequently, the producer price does not change: $p_{1}=C_{m}(Y)=C_{m}\left(Y_{0}\right)=p_{0}$ and neither does the tax revenue.

Proposition 1. Under perfect competition, a change in the consumption tax such that the elasticity of the tax function increases but the consumer price stay unchanged leads to: 
(a) no change of the producer price

(b) no change in the fiscal revenue

However, the shape of the tax actually matters regarding the incidence of consumption taxes under imperfect competition. The polar case of monopoly is presented by figure 3 .

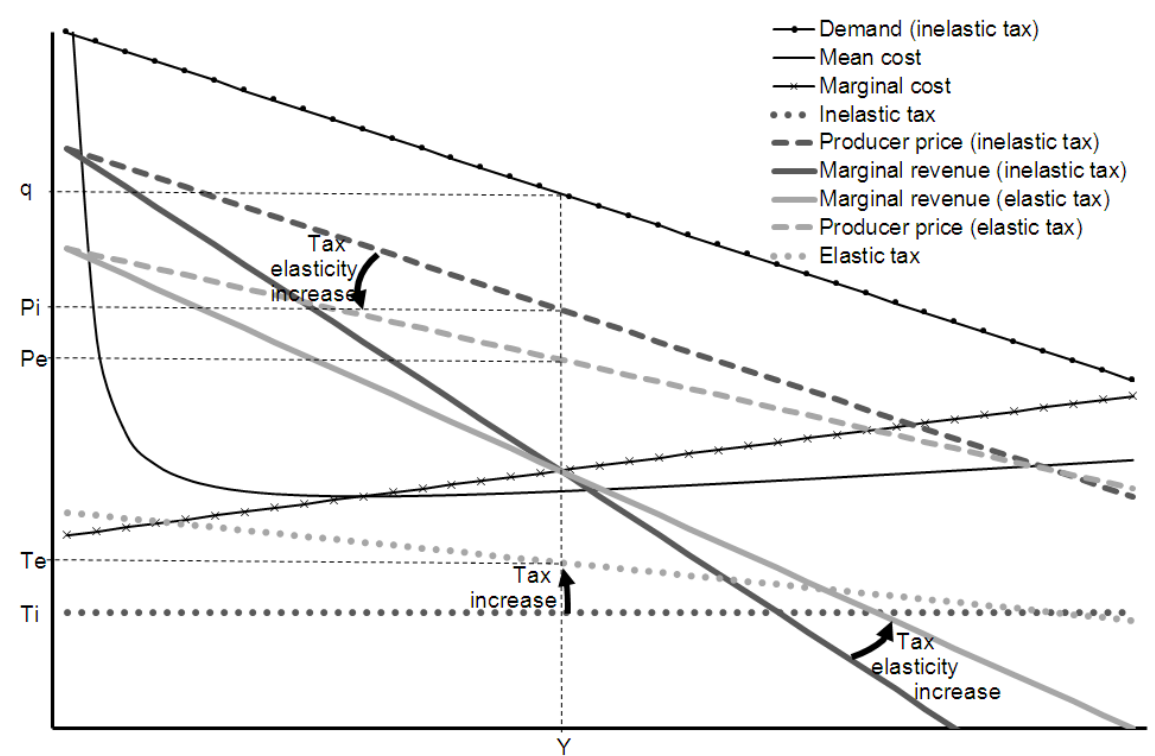

Figure 3: The elasticity of tax function for a variable rate consumtion tax

The monopoly output $Y$ is given by the intersection of the marginal cost (crossed line) and the marginal revenue (solid dark grey), itself derived from the producer price curve (dashed dark grey); the consumer price (thin dotted black line) being the inverse demand for this output. Changing the tax function $T_{0}$ for another $T_{1}$ more elastic but with the same output at equilibrium consists in drawing a new marginal revenue curve (solid light grey) with a lower shape but cutting the marginal cost curve at the same value of output $Y$. Consequently, the consumer price does not change: $q_{1}=D^{-1}(Y)=D^{-1}\left(Y_{0}\right)=q_{0}$ and neither does the marginal cost of production. However, the producer price curve changes (dashed light grey) and so does the actual producer price and therefore the tax revenue. Figure 3 shows that an increase of the elasticity of the tax function leads to a decrease of the producer price and an increase of the tax revenue.

Proposition 2. On a monopoly market, a change in the consumption tax such that the elasticity of the tax function increases but the consumer price stay unchanged leads to: 
(a) a decrease of the producer price

(b) an increase of the tax revenue

Proof. The producer price verifies the Lerner condition: $p=\frac{C_{m}}{1+\frac{1}{\epsilon_{p}}}$, where $\epsilon_{p}$ is the elasticity of the demand with respect to the producer price $p$. However, the demand function depends on the consumer price $q$ and the demand reaction parameter should be the elasticity of the demand with respect to the consumer price $\epsilon_{q}$. Given the relation between $\epsilon_{p}$ and $\epsilon_{q}$ shown by equation 1 , the producer price of a monopoly is given by equation 2 .

$$
p=\frac{C_{m}}{1+\frac{1}{\epsilon_{T} \epsilon_{q}}}
$$

As the quantity $Y$ and the consumer price $q$ are the same in $E_{0}$ and $E_{1}$, the values of the marginal cost of production and the elasticity of demand with respect to the consumer price are also the same. Therefore, the difference between $p_{0}$ and $p_{1}$ comes only from the difference between $\epsilon_{T_{0}}$ and $\epsilon_{T_{1}}$. The quantity produced and the consumer price being equal, the producer price decreases with respect to the elasticity of the consumption $\operatorname{tax} \epsilon_{T}$. Q.E.D.

The consumer share in the tax burden decreases with the elasticity of the tax; the producer share increases. This result generalizes Suits and Musgrave (1953) for a general form of consumption taxes as the elasticity of per unit consumption taxes is lower than the elasticity of ad valorem consumption taxes.

\section{Homogenous goods}

This section aims at understanding the influence of elasticity of the tax function on the incidence of consumption taxes in the case of imperfect competition. The following section studies the question of quality and diversity of consumption. The present section focuses on the matter of quantity and price and analyses production of homogenous goods. In that case, Bertrand competition leads to equilibria where the producer price is equal to marginal cost of production. The consequence regarding the purpose of the present paper is that elasticity of the tax function has no impact on consumption tax incidence, as it is the case under perfect competition. Therefore, imperfect competition in market for homogenous goods is analysed in a Cournot oligopoly model.

Such models have been criticed under argument that quantity competition is less credible than price competition. However, pure Bertrand competition assumes production follows directly 
demand without capacity constraints, which is not far more credible. Furthermore Kreps and Scheinkman (1983) shows that a game where firms invest in stage one (implying capacity constraints for the second stage) then price competition occurs in the second stage gives the same output and prices as Cournot competition. See Tirole (1988) for discution of the Kreps-Scheinkman game and $\mathrm{Wu}$ et al. (2012) for its extension to the case of non concave demand.

The present section is based on the Cournot oligopoly model with conjectural variations developped to take into account the possibility of collusion and free entrance on the market. This Cournot oligopoly model has been used by Katz and Rosen (1985); Stern (1987); Besley (1989) to evualuate consumption tax incidence, then by Delipalla and Keen (1992) to show the difference of incidence of unit and ad valorem consumption taxes and Carbonnier (2009) to show the difference of consumption tax shifting upwards and downwards in the short run. To understand specifically the effect of entry in the market, the first subsection considers a closed oligopoly then the second one allows for free entry.

\subsection{Closed oligopoly}

Let us consider $n$ firms with the cost function $C\left(y_{i}\right)$ where $C(0)=K$ is the fixed cost. Each firm anticipates the reaction of its competitiors such as $\left.\frac{\partial Y_{-i}}{\partial y_{i}}\right|^{a}=\alpha \frac{Y_{-i}}{y_{i}}$. Therefore, Cournot-Nash oligopoly corresponds to $\alpha=0$. Parameter $\alpha$ measures the collusion on the market: with $\alpha=-\frac{1}{n-1}$ the model is equivalent to perfect competition and with $\alpha=1$ it is equivalent to monopoly. The model is solved at the symmetric equilibrium. Hence, the overall change in production anticpated by each firm is then given by equation 3 .

$$
\left.\frac{\partial Y}{\partial y_{i}}\right|^{a}=n\left(\alpha+\frac{1-\alpha}{n}\right)=\gamma n
$$

Parameter $\gamma=\alpha+(1-\alpha) / n$ measure the degree of competition in the market, the model is equivalent to perfect competition if $\gamma=0$, to Cournot-Nash oligopoly if $\gamma=\frac{1}{n}$ and to monopoly if $\gamma=1$. It means that firm $i$ anticipate a production $Y_{0}$ if it exists the market, and that the total output is $Y=Y_{0}+\gamma n y_{i}$ if it produces $y_{i}$. The profit of each firm is given by equation 4

$$
\Pi_{i}=p y_{i}-C\left(y_{i}\right)
$$

For choosing the level of production that maximizes its profits, the firms anticipates a price variation due to their output variation such as in equation 5.

$$
\left.\frac{\partial p}{\partial y_{i}}\right|^{a}=\left.\frac{\partial p}{\partial q} \frac{\partial q}{\partial Y} \frac{\partial Y}{\partial y_{i}}\right|^{a}=\frac{p}{q} \frac{1}{\epsilon_{T}} \frac{q}{Y} \frac{1}{\epsilon_{D(q)}} n \gamma=\frac{n \gamma p}{Y \epsilon_{T} \epsilon_{D(q)}}
$$


Therefore the first order condition of the profit maximization is given by equation 6 and the second order condition is given by 7 .

$$
\begin{gathered}
p=\frac{C_{m}(y)}{1+\frac{\gamma}{\epsilon_{T} \epsilon_{D(q)}}} \\
\frac{n \gamma p}{Y \epsilon_{T} \epsilon_{D(q)}}\left(1+\frac{\gamma}{\epsilon_{T} \epsilon_{D(q)}}\right)+\frac{p n \gamma^{2} F}{\epsilon_{T} \epsilon_{D(q)}^{2}}-C_{m}^{\prime}<0
\end{gathered}
$$

Where $F=\frac{q}{\epsilon_{D(q)}} \frac{\partial \epsilon_{D(q)}}{\partial q}$ is the elasticity of the demand elasticity. These equations allows to understand the impact of the shape of the consumption tax on its incidence.

Proposition 3. In the case of a closed Cournot oligopoly, a change in the consumption tax such that the elasticity of the tax function increases but the consumer price stay unchanged leads to:

(a) a decrease of the producer price

(b) an increase of the fiscal revenue

Proof. Comparing to equilibria with the same consumer price $q$, and therefore the same marginal cost of production and the same demand elasticity, equation 6 shows directly that the producer price is lower when the elasticity of the consumption tax is larger. Q.E.D.

What appens at equilibrium may be represented by figure 3 of the monopoly case. The difference is that the producer price curve is no more $T^{-1}\left[D^{-1}(y)\right]$ but it is $T^{-1}\left[D^{-1}\left(Y_{0}+\gamma n y_{i}\right)\right]$. Furthermore, increasing the elasticity of the tax function but decreasing the value of the tax in order to keep the same fiscal revenue results in a decrease of the consumer price and an increase of the output. However, such a tax reform is not Pareto improving because of profit decrease, but it surely increase the social surplus.

\section{$3.2 \quad$ Free entry}

Seade (1980) introduced free entry in this kind of Cournot oligpoly. The equilibrium is characterized by the equation 6 of the maximization of profit and the equation 8 of zero profit because of the free entry.

$$
\frac{Y}{n} p=C\left(\frac{Y}{n}\right)
$$

In that case, an increase in the elasticity of the tax, even if it let the consumer price and the total output unchanged, modifies the number of firms and their individual production. The change in the producer price is not ambiguous. 
Proposition 4. In the case of a Cournot oligopoly with free entry, a change in the consumption tax such that the elasticity of the tax function increases but the consumer price stay unchanged leads to:

(a) a decrease of the producer price

(b) an increase of the fiscal revenue

(c) a decrease of the number of firms

(d) an increase of the output per firm

Proof. Mixing equations 6 and 8, it appears that equation 9 is verified at the equilibrium.

$$
\frac{C_{M}}{C_{m}}=\frac{1}{1+\frac{\gamma}{\epsilon_{T} \epsilon_{D(q)}}}
$$

Where $C_{m}$ is the marginal cost of production and $C_{M}$ the mean cost. As $1+\frac{\gamma}{\epsilon_{T} \epsilon_{D(q)}}<1$, the mean cost is larger than the marginal cost, which means that the mean cost decreases with respect to the output. With the assumption that the marginal cost does not decrease with respect to output, the ratio $\frac{C_{M}}{C_{m}}$ decreases with respect to the output. Equation 9 shows that it also decreases with respect the tax elasticity $\epsilon_{T}$. Hence, the output per firm $y$ increases with respect to the tax elasticity. As the consumer price and the total output are constant, the number of firms decreases. In addition, the free entry condition 8 establishes that the producer price $p$ is equal to the mean cost of production. As the individual output increases and the mean cost decreases, the producer price decreases. Q.E.D.

The graphical representation of this equilibrium is presented figure 4 . In that case, the entry occurs in the market whenever postive profit remains. Hence, $Y_{0}$ increases and the anticipated producer price curve $T^{-1}\left[D^{-1}\left(Y_{0}(n) \gamma n y_{i}\right)\right]$ is translated downard such as it becomes tangent to the mean cost curve. When the elasticity of the tax function increases, the slope of this producer price curve decreases, so the the point of tangency move along the mean cost curve to a lower mean cost, which leads to a lower producer price.

As in the short run, there exists a way of increasing the elasticity of the tax function which allows to simultaneously increase fiscal revenue and output and decrease consumer price. The difference is that profit stay zero. The upper elasticity equilibrium Pareto dominates the lower elasticity equilibrium because the gains in terms of fiscal revenue and consumer surplus (due to consumer price decrease and consumption increase) are obtained not by profit decrease but by production cost decrease (less firms and therefore less fixed costs). 


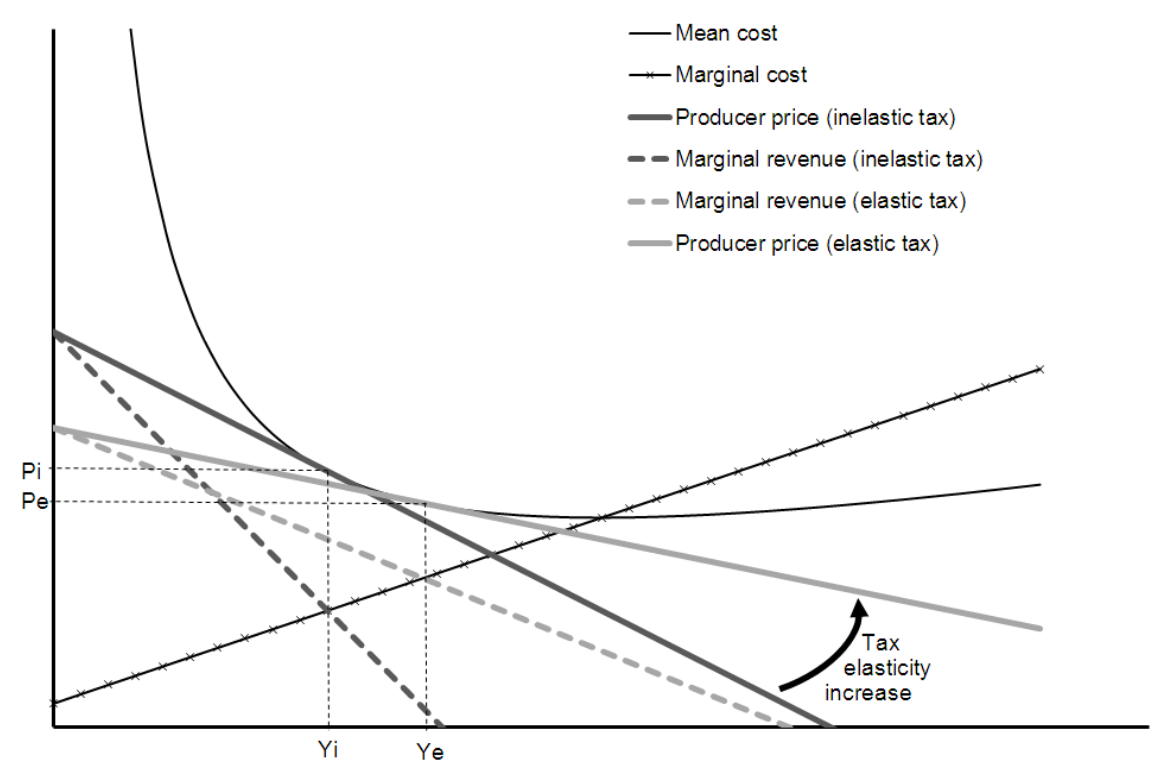

Figure 4: The elasticity of tax function for a variable rate consumtion tax

\section{Differentiated products}

Previous results are univoque in the long run: increasing elasticity of the tax function is welfare improving. However, an important dimension has been forgotten: the quality of goods and their heterogeneity. Indeed, in the long run, an increase of the elasticity of the tax function leads to less firms, which means less variety. If consumers' utility increases with the variety of consumption, it may leads to welfare decline. The present section aims at considering this through models of heterogenous production. A very general framework is considered, first in the short run (4.1) then in the long run (4.2).

\subsection{Differentiated products in the short run}

A very general Bertrand competition model is considered, based on Anderson et al. (2001b,a). In this model, $n$ firms produce differentiated goods with the same marginal cost $c$ and the same fixed cost $K$. Each producer $i$ faces a demand $D\left(q_{i}, q_{-i}\right)$ wich is symmetric and depend negatively on the consumer price $q_{i}$ of the variety $i$ and positively on the consumer price $q_{-i}$ of other varieties. The profit of firm $i$ is given by equation 10 .

$$
\pi_{i}=\left(p_{i}-c\right) D\left[T\left(p_{i}\right), T\left(p_{-i}\right)\right]-K
$$


And the first order condition of the Bertrand-Nash equilibrium is given by equation 11

$$
\left(p_{i}-c\right) \frac{\partial D\left[T\left(p_{i}\right), T\left(p_{-i}\right)\right]}{\partial p_{i}}+D\left[T\left(p_{i}\right), T\left(p_{-i}\right)\right]=0
$$

This problem is solved at the symetric equilibrium using the Chamberlain demand elasticities of

curves $d d$ and $D D: \epsilon_{d d}=\frac{q^{*}}{D} \frac{\partial D}{\partial q_{i}}$ and $\epsilon_{D D}=\frac{q^{*}}{D} \frac{\partial D}{\partial q}$. The elasticity of the slope of the $d d$ curve is $\epsilon_{m}=$ $\frac{q^{*}}{\partial q_{i}} \frac{\frac{\partial D}{\partial q_{i}}}{\partial q}$. As in Anderson et al. (2001b), $\epsilon_{D D}>\epsilon_{d d}$ and the stability condition is $\epsilon_{d d}+\epsilon_{D D}-\epsilon_{m}<0$.

Proposition 5. In the case of a Bertrand oligopoly in the short run, a change in the consumption tax such that the elasticity of the tax function increases but the consumer price stay unchanged leads to:

(a) a decrease of the producer price

(b) an increase of the fiscal revenue

Proof The first order condition applied at the symetric equilibrium gives $p_{i}-c=-\frac{D\left(q^{*}, q^{*}\right)}{\frac{\partial D\left(q^{*}, q^{*}\right)}{\partial q_{i}} \frac{\partial q_{i}}{\partial p_{i}}}$. Therefore $p^{*}=c-\frac{q^{*}}{\epsilon_{d d} \frac{\partial q}{\partial p}}=c-\frac{p^{*}}{\epsilon_{d d} \epsilon_{T}}$. Consequently, the producer price is given by equation 12 .

$$
p^{*}=\frac{c}{1+\frac{1}{\epsilon_{T} \epsilon_{d d}}}
$$

Hence, the producer price decreases with respect to the tax elasticity. Q.E.D.

\subsection{Differentiated products in the long run}

This general model of Bertrand oligopoly is more complex to solve in the long run. In particular, additional hypotheses should be assumed, mainly regarding the way the demand evolve with respect to the number of varieties present on the market. The model is first modified by the addition of the variable $n$ of the number of firms in the demand function for each firm: $D\left(q_{i}, q_{-i}, n\right)$ with the hypothesis that the demand for each variety decreases with respect to the number of firms: $\epsilon_{n}=\frac{n}{D} \frac{\partial D}{\partial n}<0$. An additional hypothesis should be assumed, which is that competition lower prices: the consumer price $q$ should decline whith respect to the number of firm. Anderson et al. (2001b) demonstrate that this hypothese is equivalent to condition 13.

$$
\epsilon_{n}<\epsilon_{q n}
$$

Where $\epsilon_{q n}=\frac{n}{\frac{\partial D}{\partial q_{i}}} \frac{\partial \frac{\partial D}{\partial q_{i}}}{\partial n}$ is the elasticity of the $d d$ curve slope with respect to $n$. Condition 13 may be rewritten in terms of the variations with respect to the number of varities of the elasticity of the 
$d d$ curve, as presented in condition 14 .

$$
\frac{\partial \epsilon_{d d}}{\partial n}<0
$$

Indeed, $\frac{\partial \epsilon_{d d}}{\partial n}=-\frac{q \frac{\partial D}{\partial n}}{D^{2}} \frac{\partial D}{\partial q_{i}}+\frac{q}{D} \frac{\partial \frac{\partial D}{\partial q_{i}}}{\partial n}=-\frac{\epsilon_{d d}}{n}\left(\epsilon_{n}-\epsilon_{q n}\right)$, and therefore - as the elasticity of the $d d$ curve is negative - this elasticity decreases with respect to the number of firm if and only if $\epsilon_{n}<\epsilon_{q n}$. This result is very intuitive: when the number of varieties increases, the possibilities of substitutions are larger and the consumers are more elastic. Two equations are needed to solve the equilibrium, the first order condition 12 and the zero profit condition 15.

$$
p^{*}=c+\frac{K}{D\left(q^{*}, q^{*}, n\right)}
$$

However, the impact of $\epsilon_{T}$ on the producer price is less transparent in the present case. Previously, $\epsilon_{d d}$ (or $\epsilon_{q}$ for the homogenous case) was invariant because the change of elasticity of the tax function was operated at constant consumer price $q$. Now, the demand - and consequently the demand elasticity - depends not only on the consumer price $q$ but also on the number of varieties, which is not constant anymore. Therefore, the variation of the producer price depends on the derivative of the product $\epsilon_{T} \epsilon_{d d}$ with respect to the change of the elasticity of the tax function. The variation of the producer price occurs in the same way as those of this product (e.g.: equation 12). The variation of the demand fo a given firm occurs in the opposite direction as those of the producer price (e.g.: equation 15), and therefore in the opposite direction as those of the product $\epsilon_{T} \epsilon_{d d}$. The variation of the number of firms occurs in the opposite direction as those of the demand for a given firm (because $\epsilon_{n}$ is negative), and therefore in the same way as those of the product $\epsilon_{T} \epsilon_{d d}$. The derivative of this product with respect to the elasticity of the tax function (at constant consumer price $q$ ) may be expressed as in equation 16.

$$
\frac{\partial \epsilon_{T} \epsilon_{d d}}{\partial \epsilon_{T}}=\epsilon_{d d}+\epsilon_{T} \frac{\partial n}{\partial \epsilon_{T}} \frac{\partial \epsilon_{d d}}{\partial n}
$$

Lemma 1. The product $\epsilon_{T} \epsilon_{d d}$ decreases with respect to the elasticity of the tax function.

Proof. This lemma could be demonstrated by reductio ad absurdum. If $\frac{\partial \epsilon_{T} \epsilon_{d d}}{\partial \epsilon_{T}}$ were positive so would be $\frac{\partial n}{\partial \epsilon_{T}}$ (following arguments of the previous paragraph). In addition, $\epsilon_{d d}$ is negative and $\epsilon_{T}$ is positive. Furthermore, condition 14 of the deflationnist effect of competition states that $\frac{\partial \epsilon_{d d}}{\partial n}$ is negative. Consequently, both terms of the right hand side of equation 16 would be negative and so would be $\frac{\partial \epsilon_{T} \epsilon_{d d}}{\partial \epsilon_{T}}$. Q.E.D. 
From these results may be derived the variations of the model parameters when the elasticity of the tax function is increased in a such way that the consumer price keeps unchanged: the producer price diminishes and the number of varieties are reduced and the demand for each remaining firms increases. As the total output $Y$ is the product of the number of firms and the individual demand they face, this total output increases if $\epsilon_{n}<-1$ and decreases if $\epsilon_{n}>-1$. For the following, condition 17 is assumed.

$$
-1<\epsilon_{n}<0
$$

The fact it is negative have been assumed earlier. The assumption of $\epsilon_{n}$ being larger than -1 comes from the love for variety hypothesis. The inequality $\epsilon_{n}<-1$ would imply that the global demand for the whole set of varieties increases when the number of varieties is reduced at constant consumer prices. It would mean that consumers dislike variety.

Proposition 6. In the case of a Bertrand oligopoly in the long run, if competition is deflationnist and consumers prefer variety (hypotheses 13 and 17), a change in the consumption tax such that the elasticity of the tax function increases but the consumer price stay unchanged leads to:

(a) a decrease of the producer price, the number of firms and the total output

(b) an increase of the output per remaining firm

(c) an increase then a decrease of the fiscal revenue: there exists a positive and finite elasticity of the tax function which maximizes the fiscal revenue at constant consumer price

Proofs. The $(a)$ and $(b)$ results have been demonstrated previously. As a matter of the fiscal revenue $F R$, it is the product of the of the equivalent unitary tax $t=q-p$ and the total output $Y$. Yet, $Y=n D$, so $\frac{\partial Y}{\partial \epsilon_{T}}=\frac{\partial n}{\partial \epsilon_{T}} D+n \frac{\partial D}{\partial \epsilon_{T}}$. Due to the definition of $\epsilon_{n}, \frac{\partial Y}{\partial \epsilon_{T}}=n\left(1+\frac{1}{\epsilon_{n}}\right) \frac{\partial D}{\partial \epsilon_{T}}$. Furthermore, condition 15 implies that $\frac{\partial D}{\partial \epsilon_{T}}=-\frac{D^{2}}{K} \frac{\partial p}{\partial \epsilon_{T}}$. It follows that $\frac{\partial F R}{\partial \epsilon_{T}}=-Y \frac{\partial p}{\partial \epsilon_{T}}\left[1+\frac{q-p}{p-c}\left(1+\frac{1}{\epsilon_{n}}\right)\right]$. Fiscal revenue increases if and only if the term between brackets is positive. This defined a threshold $T_{\epsilon_{n}}$ : when $\epsilon_{n}$ is lower than this threshold, fiscal revenue increases and it decreases when $\epsilon_{n}>T_{\epsilon_{n}}$. This threshold is given by equation 18 .

$$
T_{\epsilon_{n}}=-\frac{t}{t+\frac{c}{-\epsilon_{T} \epsilon_{d d}-1}}
$$


Previous results show that both $-\epsilon_{T} \epsilon_{d d}$ and the unitary tax $t$ increases with respect to $\epsilon_{T}$ at constant $q$. Therefore, the threshold decreases with respect $\epsilon_{T}$ keeping between 0 and 1 . When $\epsilon_{T}$ is low, the threshold is close to zero and greater than $\epsilon_{n}$ (because of condition 17): the fiscal revenue increases with the increase of the elasticity of the tax function. However, with this increase, the threshold get closer to -1, eventually being lower than $\epsilon_{n}$ (also because of condition 17): the fiscal revenue decreases with the increase of the elasticity of the tax function. Q.E.D.

The optimal elasticity of the tax function (in terms of fiscal revenue at constant consumer price) is then obtained when condition 19 is verified.

$$
\epsilon_{n}=-\frac{t}{t+\frac{c}{-\epsilon_{T} \epsilon_{d d}-1}}
$$

This optimal elasticity of the tax function maximizes the fiscal revenue at constant consumer price, but it does not maximizes the consumer surplus. Indeed, consumers purchase at the same price a quantity globally lower of less varieties of goods.

\section{Conclusion and comments}

This paper provides three original contributions. From a methodological point of view it shows how to take the shape of the tax into account in order to derive the incidence of consumption taxes: the elasticity of the tax function is the elasticity of the consumer price to the producer price and depends only on the tax schedule; it enters in a tractable manner in imperfect competition models as the ratio of price elasticity of demand from the point of view of producers and consumers.

From a theoretical point of view, it generalizes existing results on the incidence of consumption taxes, up to now limited to ad valorem and per unit consumption taxes. In imperfect competition markets, the consumer share (respectively producer share) of consumption taxes increases (respectively decreases) with respect to the elasticity of the tax function. When it does not change the quality or diversity of output (e.g.: markets for homogenous goods or closed markets for heterogenous goods) the efficiency of consumption tax is unambiguously increased by a larger elasticity of the consumption tax. However, the optimality of larger elasticity of the tax function is ambiguous when it changes the quality or diversity of output (e.g.: open markets for heterogenous goods). There exists a finite elasticity of the tax function maximizing the fiscal revenue at given consumer price (or minimizing consumer price at given fiscal revenue), but it is not optimal from the consumer point of view as it does not maximize the diversity of production. Higher elasticities of the 
tax function are clearly welfare diminishing. Lower elasticities of the tax function (at given fiscal revenue) increase both consumer price and diversity of production, highlighting the question of arbitrage between price and diversity.

From an applied public economic point of view, this article shows how the regulator may put downwards prices on imperfect competition markets by increasing the elasticity of the consumption tax on a targeted window of producer prices. As shown by welfare ambiguity on competitive markets for heterogenous goods, this kind of policy should be limited to very uncompetitive markets. In the extreme case of infinite elasticity of the tax function, the fiscality is equivalent to full price control. With finite but greater than one elasticities of the tax function, fiscal authority may perform partial price control through incentives. Keeping effective tax rates at realistic and non prohibitive levels forbids to increase the elasticity of the tax function for all possible prices: the large elasticities should target plausible prices inside a producer price window. The width of this large elasticity window and the level of the elasticity of the tax function are negatively linked.

The question of the arbitrage between prices and variety remains. In order to settle it, additional assumptions should be made and different models should be studied. These additional assumptions should allow to catch the consumers'love for variety and the way this love for variety evolves with respect to quantities consumed. Those modeling already appeared in Dixit and Stiglitz (1977) when they relaxe the CES utility hypothesis. It is the objective of Zhelobodko et al. (2012) to provide a full model of monopolistic competition in general equilibrium with various hypotheses on the variation of this love for variety. It should be relevant to study the arbitrage between price and diversity in their framework from a welfare point of view.

This would enlight this arbitrage from an individual perspective. It should also matter to understand this arbitrage in a distributive point of view. Actual consumers are heterogenous in matter of taste as much as in mater of wealth. Wealth differences should induce differences in the arbitrage between price and diversity of consumption. In that way, the choice of the elasticity of the tax function matters for the redistribution of welfare between households of different wealth. This should be studied through models with heterogeneity of consumer wealth. In addition, such studies should also point out the diversity in terms of quality of goods by the incidence of the elasticity of the tax function on the vertical diversity of goods. This should also raised some redistributive issues. 


\section{References}

Anderson, S. P., de Palma, A., and Kreider, B. (2001a). The efficiency of indirect taxes under imperfect competition. Journal of Public Economics, 81(2):231-251.

Anderson, S. P., de Palma, A., and Kreider, B. (2001b). Tax incidence in differentiated product oligopoly. Journal of Public Economics, 81(2):173-192.

Besley, T. (1989). Commodity taxation and imperfect competition : A note on the effects of entry. Journal of Public Economics, 40(3):359-367.

Besley, T. J. and Rosen, H. S. (1999). Vertical externalities in tax setting: Evidence from gasoline and cigarettes. NBER Working Papers, 6517.

Carbonnier, C. (2007). Who pays sales taxes? evidence from french vat reforms, 1987-1999. Journal of Public Economics, 91(5-6):1219-1229.

Carbonnier, C. (2009). Differing price adjustments to rises and falls in vat rates: An empirical analysis based on the 1995 and 2000 french reforms. Economie et Statistique, 413:3-20.

Carbonnier, C. (2011). Shifting on prices of per unit and ad valorem consumption taxes, estimation on prices of alcoholic beverages in france. THEMA Working Papers 2011-20, THEMA (THéorie Economique, Modélisation et Applications), Université de Cergy-Pontoise.

Cournot, A. (1838). Recherches sur les principes mathematiques de la theorie des richesses. Oeuvres complètes Tome VIII. C.N.R.S. and Librairie philosophique J. Vrin, Paris, 1980.

Delipalla, S. and Keen, M. (1992). The comparison between ad valorem and specific taxation under imperfect competition. Journal of Public Economics, 49(3):351-367.

Delipalla, S. and O'Donnell, O. (2001). Estimating tax incidence, market power and market conduct: The european cigarette industry. International Journal of Industrial Organization, 19(6):885-908.

Dixit, A. K. and Stiglitz, J. E. (1977). Monopolistic competition and optimum product diversity. American Economic Review, 67(3):297-308. 
Fullerton, D. and Metcalf, G. E. (2002). Tax incidence. In Auerbach, A. J. and Feldstein, M., editors, Handbook of Public Economics, volume 4 of Handbook of Public Economics, chapter 26, pages 1787-1872. Elsevier.

Katz, M. L. and Rosen, H. S. (1985). Tax analysis in an oligopoly model. NBER Working Papers 1088, National Bureau of Economic Research, Inc.

Kreps, D. M. and Scheinkman, J. A. (1983). Quantity precommitment and bertrand competition yield cournot outcomes. Bell Journal of Economics, 14(2):326-337.

Quesnay, F. (1759). Le tableau économique, trans: The Economic Table. University Press of the Pacific, Honolulu, Hawaii, 2004 edition.

Ricardo, D. (1821). The Principles of Political Economy and Taxation. Dover publication, Mineola, New-York, 2004 edition.

Seade, J. K. (1980). On the effects of entry. Econometrica, 48(2):479-89.

Smith, A. (1776). An Inquiry into the Nature and Causes of the Wealth of Nations. University of Chicago Press, Chicago, Illinois, 1977 edition.

Stern, N. (1987). The effects of taxation, price control and government contracts in oligopoly and monopolistic competition. Journal of Public Economics, 32(2):133-158.

Suits, D. and Musgrave, R. (1953). Ad valorem and unit taxes compared. Quarterly Journal of Economics, 67:598-604.

Tirole, J. (1988). The Theory of Industrial Organization. The MIT Press, Cambridge, Massachusetts, fourth edition.

Wicksell, K. (1896). Finanztheoretische Untersuchungen nebst Darstellung and Kritik des Steuerwesens Schwedens. Gustav Fisher, Jena.

Wu, X.-w., Zhu, Q.-t., and Sun, L. (2012). On equivalence between cournot competition and the kreps-scheinkman game. International Journal of Industrial Organization, 30(1):116-125.

Zhelobodko, E., Kokovin, S., Parenti, M., and Thisse, J.-F. (2012). Monopolistic competition: Beyond the constant elasticity of substitution. Econometrica, 80(6):2765-2784. 